\title{
BMJ Open Did previous involvement in research affect recruitment of young people with cerebral palsy to a longitudinal study of transitional health care?
}

\author{
Elena Guiomar Garcia Jalón (D) , ${ }^{1}$ Hanna Merrick, ${ }^{2}$ Allan Colver, ${ }^{2}$ Mark Linden, ${ }^{3}$ The \\ Transition Collaborative Group, On behalf of the Transition Collaborative Group
}

To cite: Garcia Jalón EG, Merrick $\mathrm{H}$, Colver A, et al. Did previous involvement in research affect recruitment of young people with cerebral palsy to a longitudinal study of transitional health care? BMJ Open 2020;10:e035525. doi:10.1136/ bmjopen-2019-035525

- Prepublication history for this paper is available online. To view these files, please visit the journal online (http://dx.doi. org/10.1136/bmjopen-2019035525).

Received 04 November 2019 Revised 22 April 2020 Accepted 17 June 2020

Check for updates

(C) Author(s) (or their employer(s)) 2020. Re-use permitted under CC BY. Published by BMJ.

${ }^{1}$ School of Social Sciences, Queen's University Belfast, Belfast, UK

${ }^{2}$ Institute of Health and Society, Newcastle University, Newcastle upon Tyne, UK

${ }^{3}$ School of Nursing and Midwifery, Queen's University of Belfast, Belfast, UK

Correspondence to

Elena Guiomar Garcia Jalón;

e.garciajalon@qub.ac.uk

\section{ABSTRACT}

Objective To assess whether being contacted about or participating in previous research and method of approaching potential participants affected recruitment to a transition study from child to adult healthcare services of young people with cerebral palsy (CP).

Design and methods Young people with CP aged 14-18 years without severe intellectual impairment were identified from regional registers of $\mathrm{CP}$ in Northern Ireland and the North of England. $\chi^{2}$ and Mann-Whitney $\mathrm{U}$ tests were used to assess differences in $\mathrm{CP}$ and sociodemographic characteristics between those recruited and those who refused. Logistic regression was used to assess contact about and recruitment to previous research and method of approach as predictors of recruitment, controlling for demographic and $\mathrm{CP}$ characteristics. Results Of the 410 young people who were approached; 162 did not respond and of the 248 who responded, 96 $(23 \%)$ were recruited. There were significant differences between those recruited and those who refused in age and number of previous studies they had participated in. Those who were older or who had previously been approached about research were more likely to be recruited to our study. However, those who had been recruited to previous studies were more likely to refuse to join our study. Conclusions The method of approach to potential participants did not affect recruitment. Older adolescents and those who had been approached about previous research were more likely to take part in our study, although there was evidence of research fatigue because if they had actually been recruited to the previous studies they were less likely to join our study. Recruitment of adolescents to studies remains challenging.

\section{INTRODUCTION}

There is little evidence about effective strategies for recruiting young people to research studies, in particular those with long-term conditions. ${ }^{1-4}$ Poorer health outcomes have been reported in this age group for nonresponders to research invitations. ${ }^{5}$ One difficulty is that many adolescents may not want to be reminded of their condition or do not consider themselves to be 'ill' ${ }^{67}$ Problems with
Strengths and limitations for this study

- Study subjects were recruited from two populationbased registers which used the same definition, severity and classification of cerebral palsy subtypes, and both confirmed information for cases at age 5 years.

- The study of the potential effect of prior involvement in research on recruitment was novel.

- Socioeconomic status could not be fully controlled for due to the lack of equivalence between the deprivation indices used in Northern Ireland and England.

- Analysis of the effect of previous involvement in research was limited to the number of studies; it could not take account of the type of study or the consent procedures.

- Young people who had been approached about or had taken part in three or more studies had to be treated as a single category due to small numbers.

recruitment can lead to bias due to differences between those who consent and those who do not. ${ }^{8-13}$ Using disease-specific registers as sampling frames can reduce the risk of bias, ${ }^{14}$ but there may be issues with research fatigue if a register is used for many studies.

The Transition Research Programme (http://research.ncl.ac.uk/transition/index. html) includes a longitudinal study examining transition from child to adult healthcare services, with young people with cerebral palsy (CP) as one exemplar group. This longitudinal study offered the opportunity to evaluate potential differences in recruitment of young people with CP using two population-based UK registers for which participation in previous research was known, the North of England Collaborative CP Survey (NECCPS) $)^{15}$ and the Northern Ireland CP Register (NICPR). ${ }^{16}$ Equally, differences in the operating procedures of the two registers allowed assessment of the effect of Direct (through the researcher from the register) and Indirect (through a 
clinician known to the family) contacts with families on their decision to take part in research.

The goal of this study was to investigate whether being contacted about or participating in previous research and method of approaching potential participants (direct vs indirect) affected recruitment to a research study.

\section{METHODS}

\section{Patient and public involvement}

Patients and the public were not involved in the design, conduct, reporting or dissemination of this particular study. However, the Transition Research Programme, which provided data for this study, included Representatives of patient organisations on the External Advisory Board and a young person working group which generated a publication. ${ }^{17}$

\section{Study design and participants}

For the purpose of this study, we used the following definitions:

Transition study: the longitudinal study included in the Transition Research Programme which examined transition from child to adult healthcare services, with young people with $\mathrm{CP}$ as one exemplar group.

Potentially eligible: young people identified from two registers of CP, the NECCPS ${ }^{15}$ and the NICPR. ${ }^{16}$

Eligible: young people confirmed to meet the inclusion criteria.

Approached: young people approached about joining the transition study.

Not-approached: young people who could not be traced or the research team was advised not to approach.

Responders: those approached who responded; they either then declined to take part or were recruited into the transition study.

Non-responders: those approached who did not respond to the initial or follow-up letters.

Recruited: those approached who responded and consented to take part in the transition study.

Refusers: a combined group which included nonresponders (passive refusal) and responders who declined to take part in the transition study (active refusal).

Direct approach: when young people and their families were contacted through the researcher from the register.

Indirect approach: when young people and their families were contacted through a clinician known to the family.

Young people were eligible for inclusion in the transition study if aged between 14 and 18 years 11 months, did not have severe intellectual impairment and could self-report. Young people were excluded if they were only seen in adult clinical services. Before approaching those potentially eligible, clinicians known to the family confirmed eligibility and contact details. All young people provided signed consent to join the transition study. For young people under 16 years of age, a parent also provided signed consent for their child to join the study.
Both the NECCPS and NICPR share a standardised definition and classification of CP; methods of ascertainment and data quality for each register have been described..$^{1516}$ Approach to the potentially eligible participants and their parents was undertaken differently for the two registers. The NECCPS is a consent-based register and therefore the researcher could contact potential participants directly by letter (direct approach). The NICPR follows an opt-out policy whereby children with CP are included unless families opt out. Thus, the NICPR asked clinicians known to the families to make the initial contact with subsequent contact by letter from the researcher (indirect approach). In both cases, two follow-up letters were sent if an initial response was not received.

\section{Data collected}

Date of birth, sex, postcode, method and date of initial approach and decision about whether to join the transition study or not were recorded. Information was provided by the CP registers on the young people's CP subtype, motor function using the gross motor function classification system (GMFCS) ${ }^{18}$ and intellectual ability as recorded when aged $4-5$ years. The registers also provided information on the number of previous studies young people had been approached about and the number they had joined.

\section{Data analysis}

Descriptive characteristics of the sample include frequencies, percentages, means and SD. Differences between recruited and refusers were assessed with $\chi 2$ test for categorical variables and Mann-Whitney $\mathrm{U}$ test for age. Differences between the subgroups within refusers, that is, non-responders (passive refusal) and responders who declined (active refusal), were also analysed. As passive and active refusal are different, it was deemed necessary to assess whether these two subgroups were different. Results from this analysis were used to define the dependent variable in the logistic regression analysis that was to follow.

Logistic regression using a standard or enter method assessed whether recruited versus refusers was predicted by method of approach (direct vs indirect) and/or the number of previous studies approached about or taken part in, controlling for: age when first approached, sex, home location and CP characteristics (subtype, GMFCS and intellectual impairment). Significance was set at $\mathrm{p}<0.05$ and results are presented as ORs and 95\% CIs. Goodness-of-fit was assessed using the Hosmer-Lemeshow test. Cox and Snell R Square and Nagelkerke R Square values were used as indicators of the variation in the dependent variable explained by the model. Analyses were performed in SPSS V.22.

\section{RESULTS}

Figure 1 shows the recruitment flow to the transition study. A total of 491 young people with $\mathrm{CP}$ were identified from the NECCPS and NICPR. Of these, 60 were found to be ineligible by the family or their clinician because 


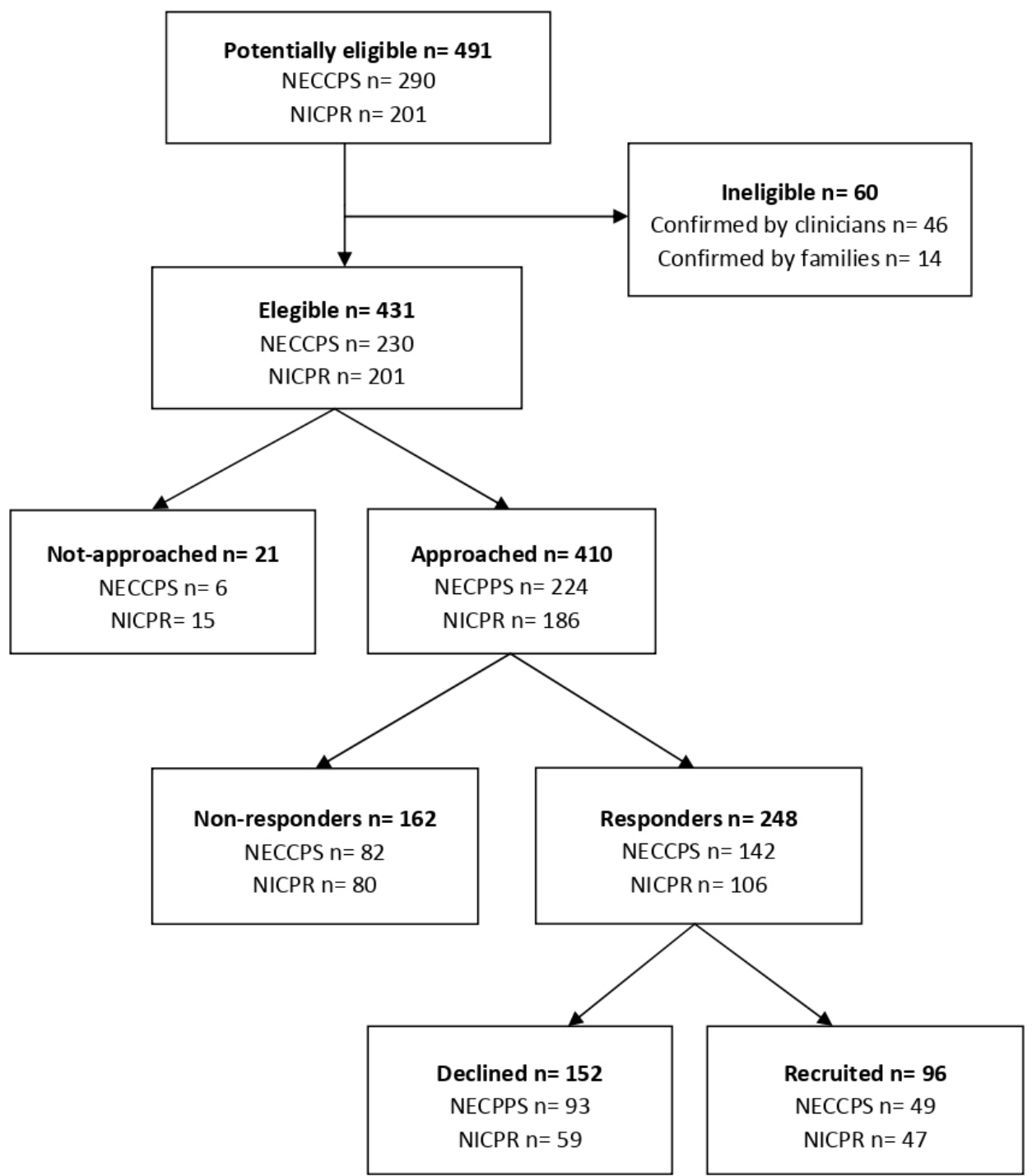

Figure 1 Recruitment flow chart. NECCPS, North of England Collaborative CP Survey; ${ }^{15}$ NICPR, Northern Ireland CP Register.

of severe intellectual impairment which had become manifest since age 5 years $(n=57)$ or because the young person had already been transferred to adult services $(\mathrm{n}=3)$. Of the 431 eligible participants, $410(95.1 \%)$ were approached. Of those who were not approached $(n=21)$, 13 had moved away or could not be traced; three were not contacted following advice from clinicians known to the family and five due to other reasons. Of those approached, $162(39.5 \%)$ did not respond. Of the remaining 248 (60.5\%), 96 agreed to take part (23.4\% of the 410 who were approached).

Recruitment: recruited versus refusers; non-responders (passive refusal) versus responders who declined (active refusal)

Table 1 shows the breakdown of characteristics for those who were approached $(n=410)$, those who were recruited $(n=96)$ and refusers $(n=314)$. Comparison between the two groups found a significant difference in age when approached $(\mathrm{p}=0.05)$, with the recruited being slightly younger (mean 16.1, $\mathrm{SD}=1.2$ ) than refusers (mean
16.4, $\mathrm{SD}=1.4$ ). There was also a significant difference in the number of previous studies they had taken part in $\left(\chi^{2}=32.6, p<0.001\right)$, with $53.1 \%$ of recruited having taken part in one or more previous studies versus $32.2 \%$ of refusers. There were no significant differences for any of the other factors.

Analyses between the subgroups of non-responders (passive refusal, $\mathrm{n}=162$ ) and responders who then declined (active refusal, $\mathrm{n}=152$ ) showed no significant differences in any of the characteristics analysed.

\section{Predictors of recruitment to the transition study}

The Hosmer-Lemeshow test found agreement between the observed and the predicted outcomes, indicating the full model was reliable $\left(\chi^{2}=8.1 ; p=0.42\right)$. The full model was significant in distinguishing between refusers and recruited $\left(\chi^{2}=36.8, p=0.004\right)$ and accounted for between $8.8 \%$ and $13.3 \%$ of the variance in refusal, with $96.7 \%$ of refusers successfully predicted. However, the model predicted only $8.6 \%$ of those recruited. Therefore, overall 
Table 1 Characteristics of the young people who were approached and comparison between recruited and refusers

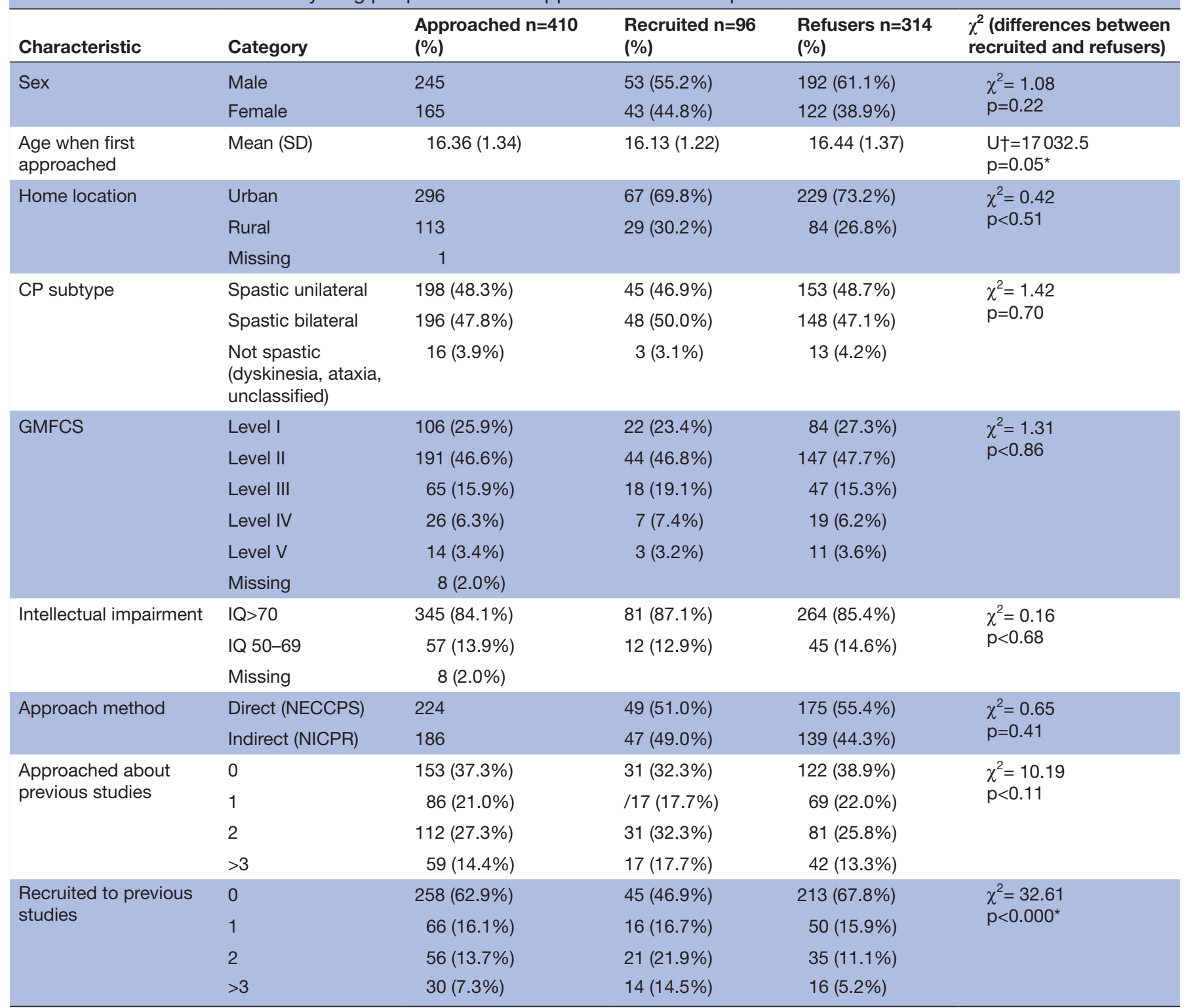

*Significant difference.

†Mann-Whitney U test.

CP, cerebral palsy; GMFCS, gross motor function classification system; NECCPS, North of England Collaborative Cerebral Palsy Survey; NICPR, Northern Ireland Cerebral Palsy Register.

$76.2 \%$ of predictions were accurate. Table 2 shows ORs with $95 \%$ CIs for each predictor variable. Only age and the number of previous studies young people had been approached about or taken part in significantly predicted refusal. The OR values indicated that an increase of 1 year in age at contact was associated with a decrease in the odds of refusal by 0.79 . OR values also indicated that being approached about many studies was associated with a decrease in the odds of refusal, especially if at least three studies (OR 0.11). In contrast, having been actually recruited to previous studies was associated with an increase in the odds of refusal, odds which rose with the number of studies recruited to.

\section{DISCUSSION}

Of the 431 eligible young people, 96 (23.4\%) were recruited to the transition study. The proportion of refusers was $76.6 \% \quad(\mathrm{n}=314)$ of whom $39.5 \% \quad(\mathrm{n}=162)$ did not respond and $37.1 \%(\mathrm{n}=152)$ declined to take part. The majority who declined stated they were not interested in the study $(n=83)$. Some young people had complex family or health situations and chose not to take part $(n=6)$ and three young people declined because they had little or no contact with healthcare services.

Previous studies assessing recruitment bias and predictors for drop-out rate in surveys with children and young people with CP reported higher recruitment rates of 
Table 2 Factors associated with refusal to take part in the transition study: logistic regression

\begin{tabular}{|c|c|c|}
\hline Variable & Category & OR $(95 \% \mathrm{Cl})$ \\
\hline \multirow[t]{2}{*}{$\begin{array}{l}\text { Method of } \\
\text { approach }\end{array}$} & $\begin{array}{l}\text { Indirect } \\
\text { (NICPR)† }\end{array}$ & 1.00 \\
\hline & $\begin{array}{l}\text { Direct } \\
\text { (NECCPS) }\end{array}$ & 1.08 (0.5 to 2.32) \\
\hline \multirow[t]{2}{*}{ Sex } & Female† & 1.00 \\
\hline & Male & 0.67 (0.4 to 1.12$)$ \\
\hline $\begin{array}{l}\text { Age when first } \\
\text { contacted }\end{array}$ & & $0.79(0.63 \text { to } 0.98)^{*}$ \\
\hline \multirow[t]{2}{*}{ Home location } & Rural† & 1.00 \\
\hline & Urban & 0.83 (0.47 to 1.47$)$ \\
\hline \multirow[t]{3}{*}{ CP subtype } & Non-spastic & 1.00 \\
\hline & $\begin{array}{l}\text { Spastic } \\
\text { unilateral }\end{array}$ & 1.6 (0.38 to 6.76$)$ \\
\hline & Spastic bilateral & 1.55 (0.38 to 6.25$)$ \\
\hline \multirow[t]{5}{*}{ GMFCS } & Level V† & 1.00 \\
\hline & Level I & 0.67 (0.14 to 3.09 ) \\
\hline & Level II & 0.87 (0.19 to 3.8$)$ \\
\hline & Level III & 1.09 (0.24 to 4.82$)$ \\
\hline & Level IV & $0.96(0.17$ to 5.24$)$ \\
\hline \multirow{2}{*}{$\begin{array}{l}\text { Intellectual } \\
\text { impairment }\end{array}$} & None† & 1.00 \\
\hline & Yes & 1.22 (0.56 to 2.67$)$ \\
\hline \multirow{4}{*}{$\begin{array}{l}\text { Approached } \\
\text { about previous } \\
\text { studies }\end{array}$} & No studies $†$ & 1.00 \\
\hline & One study & 0.66 (0.29 to 1.5$)$ \\
\hline & Two studies & 0.35 (0.11 to 1.14$)$ \\
\hline & $\begin{array}{l}\text { Three or more } \\
\text { studies }\end{array}$ & $0.11(0.02 \text { to } 0.69)^{*}$ \\
\hline \multirow{4}{*}{$\begin{array}{l}\text { Recruited to } \\
\text { previous studies }\end{array}$} & No studies† & 1.00 \\
\hline & One study & $2.95(1.1 \text { to } 7.91)^{*}$ \\
\hline & Two studies & $7.45(2.38 \text { to } 23.33)^{\star}$ \\
\hline & $\begin{array}{l}\text { Three or more } \\
\text { studies }\end{array}$ & $34.67(6.345 \text { to } 189.45)^{\star}$ \\
\hline
\end{tabular}

*Significant predictor variables in the model $p<0.05$;.

†Reference category.

CP, cerebral palsy; GMFCS, gross motor function classification system; NECCPS, North of England Collaborative Cerebral Palsy Survey; NICPR, Northern Ireland Cerebral Palsy Register.

between $72.6 \%$ and $47.3 \% .{ }^{14}{ }^{19-21}$ Although the refusal rate in those studies was lower, our non-response rate was similar to that reported by Dickinson et al $(36.7 \%)^{20}$ and marginally higher than that reported by Parkes et al $(31.5 \%){ }^{19}$

The Transition Research Programme involved young people as coresearchers ${ }^{17}$ who assisted with aspects of recruitment and retention of participants in the transition study, for example, the design of information sheets, consent and refusal forms and ensuring different routes of communication. Despite these efforts, more than half of those responders who declined reported lack of interest and more than one third of those approached did not respond. Although adult researchers and young people involved in the public and patient involvement
(PPI) work for The Transition Research Programme described positive experiences,${ }^{17}$ the impact of their work on recruitment to the transition study could not be assessed.

Transition from child to adult healthcare services has been described as a challenging time for young people with complex healthcare need resulting in issues with nonadherence to healthcare. ${ }^{22} 23$ This may not be different with research and some young people will not want to engage despite efforts to involve users in the recruitment process. There is evidence on the positive impact and challenges of PPI in health and social care research and its potential to increase recruitment of participants. ${ }^{24}{ }^{25}$ However, there is a wide variation on how evidence was assessed and reported, and most studies only collected qualitative data. ${ }^{24}{ }^{25}$ Nevertheless, researchers should consider various recruitment methods and ways in which users can assist with the recruitment of participants. ${ }^{2627}$ It is also important for researchers to report all stages of recruitment ${ }^{13}$ and PPI. ${ }^{42425}$ Compared with refusers, a higher percentage of those recruited to the transition study had taken part in one or more previous studies $(53 \%$ vs $32 \%)$ and were younger on average. The only factors predicting refusal were age, the number of previous studies eligible participants had been approached about and the number of studies they had taken part in. Older individuals were less likely to refuse and this may be because they were more independent and making their own decisions. Also, the topic of the study may have been of more interest to those who were older. The information sharing and consent process used by researchers would have conveyed to the young people that their opinion was valued, thus increasing their sense of control. ${ }^{628}$ However, these findings should be considered with caution as data for age was non normally distributed, with a positive skewness towards younger age in the recruited group and negative skewness towards older age in the refusers group; this could explain the small difference in the mean age $(0.3$ years) between recruited and refusers which was only just significant $(\mathrm{p}=0.05)$. In other studies ${ }^{14}{ }^{19-21}$ investigating recruitment of children and young people with $\mathrm{CP}$, age was not a factor which affected recruitment, but inclusion criteria covered a wide age range (4-25 years) and included participants with all levels of intellectual ability. Indeed, authors reported that those with more complex or severe CP, such as the presence of intellectual problems or not being ambulant, were more likely to take part in their research. ${ }^{21}$ This may be because their parents gave consent, whereas in the transition study, the focus was on young people giving consent and young people with severe learning disabilities were excluded. This may have contributed to why the recruitment rate was lower than in previous studies. In addition, social networking and fitting in among peers has been shown to be important for adolescents; this may be relevant for those who may have refused to take part in a study simply because it reminds them of their condition. ${ }^{6}$

Research fatigue could also be an issue affecting recruitment. This study is the only one to our knowledge 
including information on the number of previous studies eligible participants had been approached about or taken part in. Our results showed that young people who had been previously approached about research were less likely to refuse to join our study, and this became even less likely as the number of studies they had been approached about rose. However, those actually recruited to previous research were more likely to refuse to join our study, with more studies making refusal even more likely. Approaching young people about studies can be positive as they may become more aware about research and thus more likely to want to participate in it. However, researchers should be aware of the potential for research fatigue among those recruited to previous studies. Registers such as the NECCPS and the NICPR would benefit from keeping records of studies they have been involved in, who has been contacted about research and their response.

There were no significant differences between recruited and refusers regarding the method of approach (direct vs indirect) and the logistic regression model did not find method of approach to be a factor predicting refusal. Therefore, it seems unlikely that different approach methods to contact eligible participants had influenced recruitment to our study. In contrast, previous research has shown that when parents and adolescents have discordant views, adolescents are more likely to agree to participate when approached by a clinician they know. ${ }^{22}$ Equally, Dickinson $e t a l^{20}$ found that registers which used the direct approach had half the refusal rate when compared with those using indirect methods. However, both NICPR and NECCPS are based in the UK, whereas Dickinson's study involved registers from other countries (France, Italy, Sweden, Ireland and Denmark) with different data protection requirements.

The high non-response rate in this study (those who did not respond at all to the approach) is similar to rates reported in other studies. ${ }^{14}{ }^{19-21}$ Thus, there may be a subset of young people with $\mathrm{CP}$ who are not interested in research. Further, there were no significant differences in any of their impairments or sociodemographics characteristics between those who declined (active refusal) and non-responders (passive refusal). Our model only predicted between $9 \%$ and $13.7 \%$ of the variance in recruitment, and therefore other health and socioeconomic factors may influence recruitment. Non-response has been linked to poorer health behaviour and differences in socioeconomic background but few studies have focused on adolescents. ${ }^{4}$ Mattila et $a \tilde{l}^{29}$ found that non-responders to surveys among adolescents in Finland were more likely to engage in negative health behaviours, to suffer mental health disorders and to be more likely to die; these increased risks persisted to age 25 years. Although these studies focused on the general adolescent population, this developmental stage is also a challenging time in the lives of young people with chronic conditions regardless of their diagnoses. ${ }^{30} 31$ It is a time of particular risk for poorer medical outcomes and non-adherence to treatment. ${ }^{32}{ }^{33}$ As previously discussed, young people may choose not to be involved in research. PPI has the potential to optimised recruitment, although evidence for this is limited. ${ }^{24} 25$

\section{Strengths and limitations}

Both population-based registers used the same definition of CP, classification of CP subtypes and severity, and both confirmed information for cases at age 5 years. ${ }^{1314}$ While this information was used initially to determine those who were potentially eligible, subsequent contact brought the information up to date and in particular we found that level of intellectual ability was often no longer accurate.

We could not fully assess how socioeconomic status affected recruitment because of the lack of equivalence between the deprivation indices used in Northern Ireland and England. However, it was possible to compare home location (urban vs rural). Young people who had been approached about or had taken part in three or more studies had to be analysed as a single category due to small numbers. Also, analysis of the effect of previous involvement in research was limited to the number of studies without taking into consideration their nature or the consent procedures. Although the p-value for those variables showing significant differences was well below $\mathrm{p}=0.05$, there is always a possibility of type I errors.

\section{CONCLUSION}

It is encouraging that the two different methods used to approach young people with CP (direct vs indirect) did not affect recruitment. Being older and approached about previous research were associated with increased likelihood of joining the transition study. However, even in this subset of young people of CP who were research aware and committed to being involved in studies, our findings showed evidence they could experience research fatigue. There is also a subset of young people with CP who are unwilling to take part in research as shown by the high non-response rate reported in this and previous studies. Recruitment of adolescents to research studies remains difficult.

Acknowledgements The Transition Collaborative Group consists of the authors of this paper; other coapplicants: Caroline Bennett, Gail Dovey-Pearce, Ann Le Couteur, Helen McConachie, Janet McDonagh, Jeremy Parr, Mark Pearce, Tim Rapley, Debbie Reape, Luke Vale; advisors: Nichola Chater, Helena Gleeson; local investigators: Anastasia Bem, Stuart Bennett, Amanda Billson, Stephen Bruce, Tim Cheetham, Diana Howlett, Zilla Huma, Maria Lohan, Melanie Meek, Jenny Milne, Julie Owens, Nandu Thalange.We acknowledge the support of the National Institute for Health Research Clinical Research Network. We are grateful to the young people and their families who participated in the study. We thank the research assistants for their enthusiasm and dedication to contacting young people and collecting high-quality data: Kamar Ameen-Ali, Charlotte George, Kate Hardenberg, Holly Roper, Tracy Scott, Louise Ting, Rose Watson, Hazel Windmill and we thank Richard Hardy, Alison Mulvenna and Sarah Nolan for software support and administrative support.

Collaborators The Transition Collaborative Group consists of: the authors of this paper; other co-applicants: Caroline Bennett, Gail Dovey-Pearce, Ann Le Couteur, Helen McConachie, Janet McDonagh, Jeremy Parr, Mark Pearce, Tim Rapley, Debbie Reape, Luke Vale; advisors: Nichola Chater, Helena Gleeson; local investigators: Anastasia Bem, Stuart Bennett, Amanda Billson, Stephen Bruce, Tim Cheetham, 
Diana Howlett, Zilla Huma, Maria Lohan, Melanie Meek, Jenny Milne, Julie Owens, Nandu Thalange.

Contributors EGGJ, HM, AC, ML participated in the planning of the study. EGGJ had responsibility for data collection with the collaboration of HM. EGGJ was responsible for planning and conducting data analysis with the collaboration of HM and AC. EGGJ wrote the drafts of the manuscript with input by HM, AC, ML. All authors have seen and approved the version to be published.

Funding This paper summarises independent research funded by the National Institute for Health Research (NIHR) under its Programme Grants for Applied Research scheme (RP-PG-0610-10112). The views expressed are those of the authors and not necessarily those of the UK National Health Service, the NIHR or the Department of Health.

Competing interests None declared.

Patient and public involvement Patients and/or the public were not involved in the design, or conduct, or reporting or dissemination plans of this research.

Patient consent for publication Not required.

Ethics approval The transition study received a favourable ethics opinion from Newcastle and North Tyneside 1 Research Ethics Committee (12/NE/0059). All young people who agreed to take part in the transition study provided written consent.

Provenance and peer review Not commissioned; externally peer reviewed.

Data availability statement The quantitative data that support our findings are available on reasonable request from the Transition Research Programme's Chief Investigator, Allan Colver.

Open access This is an open access article distributed in accordance with the Creative Commons Attribution 4.0 Unported (CC BY 4.0) license, which permits others to copy, redistribute, remix, transform and build upon this work for any purpose, provided the original work is properly cited, a link to the licence is given, and indication of whether changes were made. See: https://creativecommons.org/ licenses/by/4.0/.

\section{ORCID iD}

Elena Guiomar Garcia Jalón http://orcid.org/0000-0003-3523-5451

\section{REFERENCES}

1 Spigarelli M. Adolescent participation in research. J Adolesc Health 2008;43:1-2.

2 Middelkoop K, Myer L, Mark D, et al. Adolescent and adult participation in an HIV vaccine trial preparedness cohort in South Africa. J Adolesc Health 2008;43:8-14.

3 Hendricks-Ferguson VL, Cherven BO, Burns DS, et al. Recruitment strategies and rates of a multi-site behavioral intervention for adolescents and young adults with cancer. J Pediatr Health Care 2013;27:434-42

4 Vangeepuram N, Townsend K, Arniella G, et al. Recruitment in clinical versus community-based sites for a pilot youth diabetes prevention program, East Harlem, New York, 2011-2012. Prev Chronic Dis 2016;13:1-8.

5 Mattila VM, Parkkari J, Rimpelä A. Adolescent survey non-response and later risk of death. A prospective cohort study of 78,609 persons with 11-year follow-up. BMC Public Health 2007;7:87.

6 McDonagh JE, Bateman B. 'Nothing about us without us': considerations for research involving young people. Arch Dis Child Educ Pract Ed 2012;97:55-60.

7 van Staa A, Jedeloo S, Latour JM, et al. Exciting but exhausting: experiences with participatory research with chronically ill adolescents. Health Expect 2010;13:95-107.

8 McCullagh S, Feinstein A. Outcome after mild traumatic brain injury: an examination of recruitment bias. J Neurol Neurosurg Psychiatry 2003;74:39-43.

9 Rahi JS, Manaras I, Tuomainen $\mathrm{H}$, et al. Engaging families in health services research on childhood visual impairment: barriers to, and degree and nature of bias in, participation. $\mathrm{Br} J$ Ophthalmol 2004;88:782-7.
10 Al-Shahi R, Vousden C, Warlow C. For the Scottish intracranial vascular malformation study (SIVMS) Steering Committee. bias from requiring explicit consent from all participants in observational research: prospective, population based study. BMJ 2005;31:942-5.

11 Hille ETM, Elbertse L, Gravenhorst JB, et al. Nonresponse bias in a follow-up study of 19-year-old adolescents born as preterm infants. Pediatrics 2005;116:e662-6.

12 Junghans $\mathrm{C}$, Feder G, Hemingway $\mathrm{H}$, et al. Recruiting patients to medical research: double blind randomised trial of "opt-in" versus "opt-out" strategies. BMJ 2005;331:940-2.

13 Hudson BF, Oostendorp LJ, Candy B, et al. The under reporting of recruitment strategies in research with children with life-threatening illnesses: a systematic review. Palliat Med 2017;31:419-36.

14 Parkes J, Kerr C, McDowell BC, et al. Recruitment bias in a population-based study of children with cerebral palsy. Pediatrics 2006;118:1616-22.

15 Colver AF, Gibson M, Hey EN, et al. Increasing rates of cerebral palsy across the severity spectrum in north-east England 1964-1993. The North of England collaborative cerebral palsy survey. Arch Dis Child Fetal Neonatal Ed 2000;83:F7-12.

16 Parkes J, Dolk H, Hill N, et al. Cerebral palsy in Northern Ireland: 1981--93. Paediatr Perinat Epidemiol 2001;15:278-86.

17 Dovey-Pearce G, Walker S, Fairgrieve S, et al. The burden of proof the process of involving young people in research. Health Expect 2019;22:465-74.

18 Palisano R, Rosenbaum P, Walter S, et al. Development and reliability of a system to classify gross motor function in children with cerebral palsy. Dev Med Child Neurol 1997;39:214-23.

19 Parkes J, Donnelly C, McDowell B, et al. Recruitment bias and characteristics of participants with severe cerebral palsy in a crosssectional survey. J Adv Nurs 2012;68:368-78.

20 Dickinson H, Parkinson K, McManus V, et al. Assessment of data quality in a multi-centre cross-sectional study of participation and quality of life of children with cerebral palsy. BMC Public Health 2006;6:273.

21 Dickinson HO, Rapp M, Arnaud C, et al. Predictors of drop-out in a multi-centre longitudinal study of participation and quality of life of children with cerebral palsy. BMC Res Notes 2012;5:300.

22 McDonagh JE, Kelly DA. The challenges and opportunities for transitional care research. Pediatr Transplant 2010;14:688-700.

23 Watson R, Parr JR, Joyce C, et al. Models of transitional care for young people with complex health needs: a scoping review. Child Care Health Dev 2011;37:780-91.

24 INVOLVE. Exploring the impact of public involvement on the quality of research.Examples. involve web site. Available: http://www.invo. org.uk/the-quality-of-research/ [Accessed 18 Feb 2020].

25 Brett J, Staniszewska S, Mockford C, et al. Mapping the impact of patient and public involvement on health and social care research: a systematic review. Health Expect 2014;17:637-50.

26 Preston J, Moneypenny S. Involving young people in the design and delivery of health research. INVOLVE Web site. Available: http://www. invo.org.uk/involvingyoung-people-in-the-design-and-delivery-ofhealth-research/ [Accessed 18 Feb 2020].

27 Sanders J, Munford R. Hidden in plain view: finding and enhancing the population of marginalized young people in research. Int J Qual Meth 2017;16:1-12.

28 Brody JL, Annett RD, Scherer DG, et al. Enrolling adolescents in asthma research: adolescent, parent, and physician influence in the decision-making process. J Asthma 2009;46:492-7.

29 Mattila V, Parkkari J, Kannus P, et al. Occurrence and risk factors of unintentional injuries among 12- to 18-year-old Finns--a survey of 8219 adolescents. Eur J Epidemiol 2004;19:437-44.

30 Bolton-Maggs PHB. Transition of care from paediatric to adult services in haematology. Arch Dis Child 2007;92:797-801.

31 Jordan A, McDonagh JE. Recognition of emerging adulthood in UK rheumatology: the case for young adult rheumatology service developments. Rheumatology 2007;46:188-91.

32 Reed-Knight B, Blount RL, Gilleland J. The transition of health care responsibility from parents to youth diagnosed with chronic illness: a developmental systems perspective. Fam Syst Health 2014;32:219-34.

33 Fredericks EM, Magee JC, Eder SJ, et al. Quality improvement targeting adherence during the transition from a pediatric to adult liver transplant clinic. J Clin Psychol Med Settings 2015;22:150-9. 